\title{
Gastrointestinal helminth parasites of pet and stray dogs as a potential risk for human health in Bahir Dar town, north-western Ethiopia
}

\author{
Tadiwos Abere, Basaznew Bogale and Achenef Melaku
}

Faculty of Veterinary Medicine, Gondar University, P.O. Box - 196, Gondar, Ethiopia

Corresponding author: Achenef Melaku, email:achenefmela@yahoo.com

Received: 05-08-2012, Accepted: 04-11-2012, Published online: 11-04-2013

\section{How to cite this article:}

Abere T, Bogale B and Melaku A (2013) Gastrointestinal helminth parasites of pet and stray dogs as a potential risk for human health in Bahir Dar town, north-western Ethiopia, Vet World 6(7): 388-392, doi: 10.5455/vetworld.2013.388-392

\begin{abstract}
Aim: A cross-sectional study was carried out from November 2011 to April 2012 to determine the prevalence and species of gastrointestinal (GI) helminth parasites in pet and stray dogs as a potential risk for human health in Bahir Dar town, northwestern Ethiopia.

Materials and Methods: A total of 384 and 46 faecal samples were collected from pet and stray dogs, respectively and examined by using standard coprologic techniques.

Results: The overall prevalence of GI helminth infection in pet and stray dogs was 75.26 and $84.78 \%$, respectively. The detected parasites with their frequencies in pet dogs were Ancylostoma caninum (78.89\%), Toxocara canis (39.79\%), Dipylidium caninum (29.75\%), Strongyloides stercoralis (29.06\%), Taeniidae (23.87\%) and Trichuris vulpis (7.95\%). Stray dogs were found more likely to be polyparasitized and presented higher prevalence of A. caninum, T. canis, S. stercoralis, Trichuris vulpis and Taeniidae $(P<0.05)$ than domiciled ones. Diphyllobothrium latum was detected only in $10.25 \%$ of stray dogs. Toxocara canis and A. caninum $(P<0.05)$ were detected more frequently in dogs with less than 6 months of age $(P<$ $0.05)$ than old age dogs. The sex or breed groups didn't significantly affect the prevalence of parasites. A significant variation was recorded $(P<0.05)$ between different feeding systems where higher prevalence was observed in uncontrolled feeding group $(82.18 \%)$ compared to controlled feeding $(32.08 \%)$.

Conclusion: Different gastrointestinal parasites in pet and stray dogs were identified in the study area that can potentially infect humans and cause serious public-health problems. Thus, concerted efforts should therefore be made to educate dog owners to embrace modern dog disease control programs and measures have to be taken on stray dogs.
\end{abstract}

Keywords: Bahir Dar, dog, Ethiopia, gastrointestinal, helminth, prevalence

\section{I ntroduction}

The domestic dog (Canis familiaris) is generally considered as the first domesticated mammal and has co-existed with man as a working partner and house pet in all eras and culture since the days of the cave dwellers [1]. Dogs perform a range of cultural, social and economic functions in society. Dogs are kept as pets and companions, for hunting, as guards or for commercial purposes. Some studies also suggest that keeping pets is associated with a higher level of selfesteem in children [2,3].

The dog population in urban and suburban regions is composed of dogs that roam only with their owners and stray dogs which are ownerless [4]. In both cases, the animals come in close contact with humans and their dwellings and act as reservoirs and transmitters of zoonotic diseases [5,6]. Gastrointestinal helminths of dogs pose serious impact both on the host and human beings. They impede the successful rearing of dogs and result in losses that are manifested

This article is an open access article licensed under the terms of the Creative Commons Attribution License (http://creativecommons. org/licenses/by/2.0) which permits unrestricted use, distribution and reproduction in any medium, provided the work is properly cited. by lowered resistance to infectious diseases, retarded growth, reduced work and feed efficiency and general ill health [7]. Uncontrolled population of stray and semi-domesticated dogs in close proximity to increasing densities of human population in urban environments is a common fact in developing countries, in conjunction with the lack of veterinary attention and zoonotic awareness, increases the risks of disease transmission [5]. Thoughtless dog breeding raises the number of stray and free-living dogs. From the aspect of transmission of diseases in urban and rural habitats, they present a high risk factor [8]. Some surveys have been conducted on the prevalence of the helminth parasites of dogs in different parts of the country [9.10]. However, there is no any information on the literature on the prevalence of gastrointestinal helminth parasites of pet and stray dogs in Bahir dar town, Therefore, the objectives of this study were to identify and determine the prevalence of GI helminth parasites of pet and stray dogs in the town.

\section{Materials and Methods}

Study area: A cross-sectional study was conducted from November 2011 to April 2012 in Bahir dar town, 
Table- 1. The overall prevalence gastrointestinal helminth infections in pet and stray dogs

\begin{tabular}{lccccc}
\hline Dogs & No. examined & No. positive & Prevalence (\%) & Chi-square & P-Value \\
\hline Pet & 384 & 289 & 75.26 & 2.056 & 0.151 \\
Stray & 46 & 39 & 84.78 & & \\
Total & 430 & 328 & 76.27 & & \\
\hline
\end{tabular}

Table-2. Prevalence of gastrointestinal helminth species detected in pet and stray dogs in Bahir Dar town

\begin{tabular}{|c|c|c|c|c|}
\hline \multirow[t]{2}{*}{ Type of parasites } & \multicolumn{2}{|c|}{ Pet dogs $(n=289)$} & \multicolumn{2}{|c|}{ Stray dogs $(n=39)$} \\
\hline & No. Positive & Prevalence (\%) & No. Positive & Prevalence (\%) \\
\hline Ancylostoma caninum & 228 & 78.89 & 33 & 84.61 \\
\hline Toxocara canis & 115 & 39.79 & 21 & 53.84 \\
\hline Strongyloides stercoralis & 84 & 29.06 & 18 & 46.15 \\
\hline Dipylidium caninum & 86 & 29.75 & 12 & 30.76 \\
\hline Taeniidae & 69 & 23.87 & 14 & 35.89 \\
\hline Trichuris vulpis & 23 & 7.95 & 8 & 20.51 \\
\hline Diphyllobothrium latum & 0 & 0.00 & 4 & 10.25 \\
\hline
\end{tabular}

north-western Ethiopia. The town is bordered by the biggest lake (Tana) and river (Blue Nile) in Ethiopia. It is located between $12^{\circ} 29^{\prime} \mathrm{N}$ latitude and $37^{\circ} 29^{\prime} \mathrm{E}$ longitude. The average annual Orainfall ranges from $1200-1600 \mathrm{~mm}$ and it has mean annual temperature of $26^{\circ} \mathrm{C}[11]$.

Study animals and sample size determination: The study animals were dogs available in Bahir dar as pet (having owner) and stray (owner less) dogs. There are about 1670 pet and more 100 stray dogs in the town [12]. The total number of pet dog required for sampling was calculated based on the formula given by Thrusfield [13]. Since, there was no information about the prevalence of the parasites in the area, 50\% expected prevalence was taken to calculate the sample size with $5 \%$ absolute precision. So the calculated sample size was 384 for pet dogs but only 46 stray dogs were sampled without any calculation. Dogs of all age group and both sexes were randomly selected. Pet dogs were categorized as pups ( $<6$ months of age), juvenile (6 months to 1 year of age) and adult dogs ( $>1$ years of age) [13].

Sample collection: A total of 384 faecal samples were collected directly from the rectum of each pet dog with the help of finger and 46 faecal samples were collected from the ground immediately after voiding by stray dogs using plastic gloves, stored in refrigerator and processed within 2-3 hours of collection at Bahir dar Regional animal disease diagnosis and investigation center. The samples were processed using direct smear, sedimentation and salt floatation technique as described by Urquhart et al. [14]. Identification of characteristic parasite eggs was made according to the morphological characteristics and key as outlined by Soulsby [7].

Statistical analysis: Raw data were entered into a Microsoft Excel spreadsheet and descriptive statistics were used to summarise the data. The prevalence was calculated for all data as the number of infected individuals divided by the number of individuals examined and multiplied by 100 to express in percentage. Chi square was used to assess the association of risk factors on the prevalence of parasites. All statistical analyses were performed using the "SPSS" statistical software and $95 \%$ confidence level was used to determine significant difference. For simplicity, only " $P$ " values were quoted.

\section{Results}

The overall prevalence of parasitism was 75.26 and $84.78 \%$ in pet and stray dogs, respectively. There was no statistical significant different $(P>0.05)$ between pet and stray dogs (Table-1).

The detected parasites with their frequencies in pet dogs were Ancylostoma caninum (78.89\%), Toxocara canis (39.79\%), Dipylidium caninum (29.75\%), Strongyloides stercoralis (29.06\%), Taeniidae (23.87\%) and Trichuris vulpis (7.95\%). Stray dogs were found more likely to be polyparasitized and presented higher prevalence of A. caninum, $T$. canis, $S$. stercoralis, Trichuris vulpis and Taeniidae $(P<0.05)$ than domiciled ones. Diphyllobothrium latum was detected only in $10.25 \%$ of stray dogs (Table-2). Concurrent infection with two or more helminth parasites was common in $73.7 \%$ of the infected pet dogs.

Out of 254 male and 130 female pet dogs, 74.80 and $76.15 \%$ were infected with gastrointestinal helminth parasites, respectively. However, there was no significant difference $(P>0.05)$ in the prevalence of gastrointestinal helminth infections between male and female dogs. Likewise, there was no significant differences $(P>0.05)$ in the prevalence of parasitic infection between local (76.70\%), exotic $(73.80 \%)$ and crossbred (76.19\%) pet dogs (Table 3 ). No significant difference $(P>0.05)$ in the prevalence of helminth infection was observed among age groups of pet dogs. The highest prevalence $(P<0.05)$ was recorded in young dogs $(83.04 \%)$ followed by puppies $(77.11 \%)$ and adults $(69.84 \%)$. Regarding the feeding systems, the prevalence of helminth parasites in uncontrolled fed dogs was $82.18 \%$ whereas $32.08 \%$ in controlled feeding $(32.08 \%)$ with a significant variation $(P<0.05)$ between them (Table-3).

Table-4 shows the distribution of gastrointestinal helminth parasites of pet dogs in Bahir dar town. Toxocara canis and A. caninum were detected more 
Table-3. Overall prevalence of gastrointestinal helminths in pet dogs based different risk factors

\begin{tabular}{|c|c|c|c|c|c|c|}
\hline Risk factors & Categories & No. examined & No. infected & Prevalence (\%) & Chi-square & P-value \\
\hline \multirow[t]{2}{*}{ Sex } & Male & 254 & 190 & 74.80 & 0.84 & 0.772 \\
\hline & Female & 130 & 99 & 76.15 & & \\
\hline \multirow[t]{3}{*}{ Age } & Puppies & 83 & 64 & 77.11 & 6.770 & 0.034 \\
\hline & Young & 112 & 93 & 83.04 & & \\
\hline & Adults & 189 & 132 & 69.84 & & \\
\hline \multirow[t]{3}{*}{ Breed of dogs } & Local & 176 & 135 & 76.70 & 0.422 & 0.810 \\
\hline & Cross & 187 & 138 & 73.80 & & \\
\hline & Exotic & 21 & 16 & 76.19 & & \\
\hline \multirow[t]{2}{*}{ Feeding system } & Controlled (cooked) & 53 & 17 & 32.08 & 61.734 & 0.000 \\
\hline & Uncontrolled (uncooked) & 331 & 272 & 82.18 & & \\
\hline
\end{tabular}

Table-4. Prevalence of parasite species in relation to age in pet dogs in Bahir Dar

\begin{tabular}{|c|c|c|c|c|c|c|}
\hline Risk factors & Categories & No. examined & No. infected & Prevalence (\%) & Chi-square & P-value \\
\hline \multirow[t]{3}{*}{ A. caninum } & Puppies & 83 & 55 & 66.27 & 8.743 & 0.013 \\
\hline & Young & 112 & 75 & 66.96 & & \\
\hline & Adult & 189 & 98 & 51.85 & & \\
\hline \multirow[t]{3}{*}{ T. canis } & Puppies & 83 & 45 & 54.22 & 35.161 & 0.000 \\
\hline & Young & 112 & 35 & 31.25 & & \\
\hline & Adult & 189 & 35 & 18.52 & & \\
\hline \multirow[t]{3}{*}{ T. vulpis } & Puppies & 83 & 1 & 1.20 & 4.314 & 0.116 \\
\hline & Young & 112 & 8 & 7.14 & & \\
\hline & Adult & 189 & 14 & 7.41 & & \\
\hline \multirow[t]{3}{*}{ S. stercoralis } & Puppies & 83 & 16 & 19.28 & 0.720 & 0.658 \\
\hline & Young & 112 & 27 & 24.11 & & \\
\hline & Adult & 189 & 41 & 21.69 & & \\
\hline \multirow[t]{3}{*}{ D. caninum } & Puppies & 83 & 19 & 22.89 & 0.786 & 0.675 \\
\hline & Young & 112 & 28 & 25.00 & & \\
\hline & Adult & 189 & 39 & 20.63 & & \\
\hline \multirow[t]{3}{*}{ Taeniidae } & Puppies & 83 & 12 & 14.46 & 2.272 & 0.321 \\
\hline & Young & 112 & 25 & 22.32 & & \\
\hline & Adult & 189 & 32 & 16.93 & & \\
\hline
\end{tabular}

frequently $(P<0.05)$ in dogs with $<6$ months of age $(P<$ $0.05)$ than adult dogs with a significant difference $(\mathrm{P}<0.05)$ between them (Table- 4$)$.

\section{Discussion}

The study showed that 75.26 and $84.78 \%$ of pet and stray dogs examined were affected by parasitic diseases, respectively. The result of this study was higher than reports of Yacob et al. [15], Endrias et al. [9], Degefu et al. [10] and Eleni et al. [16] in Ethiopia, Katagiri and Oliveria-sequeira [17] in Brazil, Maria et al. [18] in Argentina, Fok et al. [19] in Hungary, and Anene et al. [20] in Nigeria with a prevalence of 51.00, 52.86 and $64.4,54.33,52.453$ and $68.4 \%$, respectively. Higher prevalence than the result of this study was reported by Davoust et al. [21] in north-east Gabon (94.1\%), Umar [22] in Kaduna State, Nigeria (93.8\%) and Lavallen et al. [23] in Argentina (89.13\%). The difference in the frequency of the helminth parasite infections between places or countries is possibly due to the differences in climatic factors required for the biology of the parasites, veterinary facilities and public awareness to take care of the dogs. During the survey, it was noted that a large number of dogs scavenge at abattoirs and at butcher shops which frequently fed on thrown offal that are not in good hygienic condition. It is also common to find animal cadaver thrown into street where dogs communally feed on, which could be a suitable for transmission of the parasites.

Concurrent infection with two or more different species of helminths was more common than infection with one in both types of dogs. The greatest contributors were A. caninum $(78.89 \%, 84.61 \%)$ and Toxocara canis $(39.79 \%, 53.84 \%)$ in pet and stray dogs, respectively. Other worms encountered in this study included Strongyloides stercoralis, Trichuris vulpis, and tapeworms. Similar finding was also reported by Traub et al. [5], Endrias et al. [9] and Degefu et al. [10].

A similar prevalence of $A$. caninum was also reported by Jones et al. [24] in Southern Ethiopia. A lower prevalence of A. caninum was also reported from abroad countries by Umar [22] in Nigeria, Garedaghi and Mashai [25] in Tabriz, Iran, Davoust et al. [21] in North-East Gabon and Katagiri and Oliveira-Sequira [17] in Brazil. This difference may be associated with geographic location of the area, a high level awareness about dog parasites and socioeconomic status of pet owners for hygiene and make use of the available veterinary cares for their animals [26].

The overall and specific parasites prevalence recorded in the current study are strongly associated with age. The overall prevalence of helminth parasites was significantly higher in young dogs $(<1$ year-old $)$ than adult. This is partially due to parasite specific immunity usually acquired with age or probably as consequence of single or repeated exposures [27].

The result obtained in this study revealed that the difference in prevalence of gastrointestinal helminth parasite in male and female pet dogs was not statistically significant. This agrees with reports of Yacob [15] and Degefu et al. [10] conducted in Debre 
Zeit and Jimma (Ethiopia), respectively. In contrast, a study in Nigeria indicated that female dogs were more likely to contract intestinal nematodes than male dogs [21].

In this study, concurrent infection with two or more helminth parasites is common in $73.7 \%$ of the infected pet dogs. Similar observations have been reported by Degefu et al. [10] and Endrias et al. [9].

The overall prevalence of T. canis $(39.79 \%)$ recorded in the current study is higher than the previous reports of Yacob et al. [15] and Endrias et al. [9] and Degefu et al. [10] with a reported prevalence of 21, 17.1 and $25.8 \%$ in Debre Zeit, Ambo and Jimma, respectively. In addition, the prevalence of Toxocara infection reported here was higher than the earlier reports from Netherland [2]. The present study revealed that the prevalence of $T$. canis was higher in puppies $(54.2 \%)$ than adults $(18.5 \%)$. Puppies are at higher risk of infection due to transplacental and transmammary transmission and parasite-specific immunity is usually acquired with age, probably as a consequence of single or repeated exposures [14].

Tricuris vulpis had the least prevalence (7.95\%) among other gastrointestinal helminth species. This result agrees with previous reports of Garedaghi and Mashaei [25] in Tabriz, Iran with prevalence of $86.06 \%$. Less prevalence was reported Degefu et al. [10] in Jimma, Ethiopia, with prevalence of $4.7 \%$. Higher prevalence studies were found by Katagiri and Oliveira-Sequira [17] in Brazil (7.1\%), Davoust et al. [21] in North-east Gabon (49.5\%).

The prevalence of Strongyloides stercoralis revealed a prevalence of $29.06 \%$ in pet dogs and $46.15 \%$ in stray dogs. Studies conducted by Endrias et al. [9] and Eleni et al. [16] indicated a lower prevalence of S. stercoralis which accounted for 14.29 and $4.29 \%$ in Ambo and Gondar towns, respectively.

Dipylidium caninum was found with prevalence of $29.75 \%$. This had less value when compared with $75 \%$ reported by Umar [22] in Nigeria, $25.8 \%$ by Degefu et al. [10] in Jimma, Ethiopia, 25.7 by Endrias et al. [9] in Ambo town, Central Ethiopia. Less prevalence were reported in Tabriz Iran $(7 \%)$ by Garedaghi and Mashahi [25], Brazil $2.4 \%$ by Katagiri and Oliveira-Sequira [17]. The result of this parasite reveals the presence of ectoparasites in this town that used as an intermediate host to complete its life cycle.

Prevalence of Echinococus granulosus and other Taeniidae was $23.87 \%$. This result is higher than the reported prevalence of Degefu et al. [10] in Jimma town (18.3\%), Endrias et al. [9] in Ambo town (8.57\%) and Yimer et al. [28] in Addis Ababa (4.6\%). Improper feeding system and absence of owner awareness about the transmission of this parasite from row meat and offal's may result the occurrence of this parasite in the present study area.

In the present study, the prevalence in local, cross and exotic breeds was not found statistically significant. This report agrees with the previous study by Swai et al. [29] in Tanzania. This indicates that all categories have equal chance of acquiring the infection if they are exposed to infected materials.

The current study showed that feeding management had a significant influence in the prevalence of gastrointestinal helminth infections. Dogs which receive a great care by their owners had lower incidence of intestinal helminths than dogs lacking such privileges [30].

In all cases, the overall and specific parasites prevalence recorded in stray dogs in the present study was similar but with different levels with household dogs. The only difference was the presence of Diphylobothrium latum in stray dogs. This could be due to the free roaming character of stray dogs which leads them to be exposed to fish offal infected with infective stage of the adult parasite.

\section{Conclusion}

This study showed the gastrointestinal helminth parasites in pet and stray dogs in the study area were highly prevalent. In addition, the species of helminth parasites recorded in the present work have potential zoonotic importance. A combination of routinely screening faecal samples for parasites, strategic anthelmintics regimes and improved pet owner education is recommended for the control of gastrointestinal parasites in pet dogs including control of stray dog population in the study area.

\section{Authors' contribution}

$\mathrm{BB}$ was the project leader and designer in addition to editing and providing valuable comments on the manuscript. TA was responsible for data collection and draft preparation of the manuscript. AM made conceptual and editorial contributions and performed the statistical work. All authors revised and approved the final version of the manuscript.

\section{Acknowledgements}

The authors would like to thank staff members of Bahir dar Regional Veterinary Laboratory for providing the place to carry out this study and for their invaluable help throughout the study period.

\section{Competing interests}

Authors declare that they have no competing interest.

\section{References}

1. Brickner, I. (2002) The impact of domestic dogs (Canis familiaris) on wildlife welfare and conservation: a literature review. With a situation summary from Israel. University of Harare, Zimbabwe.

2. Paul, E. and Serpell, J. (1996) Obtaining a new pet dog: Effects on middle childhood children and their families. Applied Animal Behaviour Science, 47: 17-29.

3. Knobel, D. L., Laurenson, M. K., Kazwala, R. R., Boden, L. A. and Cleaveland, S. (2008) A cross sectional study of factors associated with dog ownership in Tanzania. BMC Veterinary Research, 4: 5

4. Beck, A.M., (2000) The human-dog relationship: a tale of two species. In: Macpherson CNL, Meslin FX, Wandeler AI 
(eds) Dogs, zoonoses and public health. CABI, Wallingford, pp. 1-16.

5. Traub, R.J., Robertson, I.D., Irwin, P.J., Mencke, N. and Thompson, R.C. (2005) Canine gastrointestinal parasitic zoonoses in India. Trends in Parasitology, 21: 42-48.

6. Gracenea, M., Gómez, M.S., and Torres, J. (2009) Prevalence of intestinal parasites in shelter dogs and cats in the metropolitan area of Barcelona (Spain). Acta Parasitologica, 54:73-77.

7. Soulsby, E.J.L. (1982) Helminths, Arthropods and Protozoa of Domesticated Animals. 7th edition, Bailliere Tindall, London.

8. Rowan, A. N. (1992) Shelters and pet overpopulation, statistical black hole. Anthrozoos, 5: 140-143.

9. Endrias, Z., Yohannes, S. and Berhanu, M. (2010) Prevalence of helminth parasites of dogs and owners awareness about zoonotic parasites in Ambo town, Central Ethiopia. Ethiopian Veterinary Journal, 14(2): 17-30.

10. Degefu, H., Tefera, A. and Yohannes, M. (2011) Zoonotic helminth parasites in faecal samples of household dogs in Jimma Town, Ethiopia. Journal of Public Health and Epidemiology, 3(4): 138-143.

11. CSA (2010) Central statistics Authority: Report on livestock and livestock characteristics. Vol-2. Addis Ababa,Ethiopia.

12. RADDIC (2011) Regional Animal Disease Diagnosis and Investigation centre, Annual report Bahir Dar, Ethiopia.

13. Thrusfield M. (2005) Veterinary epidemiology. $3^{\text {rd }}$ ed. Blackwell Science Ltd, London.

14. Urquhart G. M., Armour J., Duncan J. L., Dunn A. M. and Jennings F. W. (1996) Veterinary Parasitology 2 ed., Blackwell Science, pp. 261-264.

15. Yacob, H. T., Ayele, T. Fikru, R. and Basu, A. (2007) Gastrointestinal nematodes in dogs from Debre Zeit, Ethiopia. Veterinary Parasitololgy, 148: 144-148.

16. Eleni, A., Basaznew, B. and Mersha, C. (2011) Intestinal nematode parasites of dogs: prevalence and associated risk factors. International Journal of Animal and Veterinary Advance, 3(5): 374-378.

17. Katagiri, S. and Oliveira-Sequeira, T. C. (2008) Prevalence of dog intestinal parasites and risk perception of zoonotic infection by dog owners in São Paulo State, Brazil. Zoonoses Public Health, 55(8-10): 406-413.

18. Maria, F., Fontanarrosa-Dari, O, V., Julia, B. and Diego, E. (2006) An epidemiological study of gastrointestinal parasites of dogs from Southern Greater Buenos Aires (Argentina): Age, gender, breed, mixed infections, and seasonal and spatial patterns. Veterinary Parasitology, 136: 283296.

19. Fok, E., Szatmri, V., Busk, K. and Rozgonyi, F. (2001)
Prevalence of intestinal parasites in dogs in some urban and rural areas of Hungary. The Veterinary quarterly, 23: 96-98.

20. Anene, B.M., Nnaji T.O. and Chime, A.B. (1996) Intestinal parasitic infections of dogs in the Nsukka area of the Enugu State, Nigeria. Preventive Veterinary Medicine, 27: 89-94.

21. Davoust, B., Normand, T., Bourry, O., Dang, H., Leroy, E. and Bourdoiseau, G. (2008) Epidemiological survey on gastrointestinal and blood-borne helminths of dogs in north east Gabon. Onderstepoort Journal of Veterinary Research, 75: 359-364.

22. Umar, Y.A., (2009) Intestinal Helminthoses in Dogs in Kaduna Metropolis, Kaduna State, Nigeria, Iranian Journal of Parasitology, 4(1):34-39.

23. Lavallen, C.M., Dopchiz, M.C., Lobianco, E., Hollmann, P. and Denegri, G. (2011) Intestinal parasites of zoonotic importance in dogs from the District of General Pueyrredón (Buenos Aires, Argentina). Revue de Médecine Vétérinaire, 22(1): 19-24.

24. Jones, O., Kebede, N., Kassa, T., Tilahun, G. and Macias, C. (2011) Prevalence of dog gastrointestinal parasites and risk perception of zoonotic infection by dog owners in Wondo Genet, Southern Ethiopia. Journal Public health and epidemiology, 3(11):550-555.

25. Garedaghi, Y. and Mashaei, S.S. (2011) Prevalence of Gastrointestinal Helminthic Infestation in Pet and Stray Dogs in Tabriz (East-azerbaijan Province), Iran. Advances in Environmental Biology, 5(4): 735-738.

26. Schantz, P. M. (1999) Sharing the burdens: parasites of dogs and cats that infect human beings. In: Bredahuer M, ed. Pets, people and parasites. Publication 1/99 Continuing Veterinary Education. Murdoch: Murdoch University, p. 33-44.

27. Ramirez-Barrios, R. A., Barboza-Mena, G., Munoz, J., Angulo-Cubillán, F., Hernández, E. and González F. (2004) Prevalence of intestinal parasites in dogs under veterinary care in Maracaibo, Venezuela. Escalona F. Veterinary Parasitology, 121(1-2):11-20.

28. Yimer, E., Ekoro, B., Tilhun, W., Badeg, Z. and Abebe, B. (2005) Prevalence of hydatidosis in animals slaughtered at the Addis Ababa abattoir and dog Echinococcosis in Addis Ababa city. Ethiopian Veterinary Journal, 9: 151-154.

29. Swai, E.S., Kaaya, E.J., Mshanga, D.A. and Mbise, E.W., (2010) A Survey on Gastro-intestinal Parasites of NonDescript Dogs in and Around Arusha Municipality, Tanzania. International Journal of Animal and Veterinary Advance, 3(2): 63-67.

30. Hayward. M. (2004) Risk of zoonoses from dogs on sporting fields. Aust. Vet. Association. Available at: http://www. litter. vic.gov.au/resources/documents/zoonoses_sport_fields Retrieved on 18-07-2012. 